\title{
Research on Teaching Reform of Software Engineering Course based on Flipped Classroom
}

\author{
Xueming Bai \\ School of information science and technology \\ Taishan University \\ Taian, China \\ baixm@aliyun.com
}

\author{
Qian Wang \\ School of business \\ Taishan University \\ Taian, China \\ wangqiankey@126.com
}

\begin{abstract}
Based on the characteristics of the software engineering course, this paper analyzes the current situation and problems of the course teaching, and puts forward the project driven software engineering reverse classroom teaching mode reform method.
\end{abstract}

Keywords—software engineering; flipped classroom; teaching reform;education

\section{INTRODUCTION}

Software engineering is an engineering discipline which guides the development and maintenance of computer software. The system to grasp the theory and method of software talents, the necessary software project with the understanding and practice of comprehensive control ability, development ability and good communication and coordination ability and software engineering course teaching content and teaching objectives are closely related, so the software engineering curriculum plays an important role in the cultivation of professional talents of software engineering. The teaching content of software engineering is theoretical, and it is difficult to understand on the surface. In recent years, the teaching methods and means of this course have been improved continuously, and the teaching effect has been improved obviously, but there are still many problems. For example, the practice of software development and separate the basic theory and method of learning; the teaching methods of Teacher centered, ignoring students' innovative enthusiasm and initiative and cultivate students' ability of personal development; emphasis on software development, ignoring the cultivation of team spirit.

Flipped classroom is a new type of teaching mode. This kind of teaching method to the information carrier as the support, make full use of classroom time, make students change from passive recipients of knowledge to actively acquire knowledge, and cultivate students' ability of individualized learning, autonomous learning and cooperative learning. Traditionally, students in the learning process is divided into two stages: the first stage is the "knowledge", realized by the teachers in the classroom; the second stage is the "assimilation" in class by the students through the review, homework and other forms to achieve. "Assimilation" need to be flexible to use the knowledge to solve the problem, as opposed to the "knowledge" stage is more difficult, but this time it is the lack of teachers' support and guidance, students often feel frustrated and lose motivation, copying homework became a common phenomenon. The "flipped class" has reconstructed the students' learning process. The knowledge transfer is carried out by the students before the class. The "absorption and internalization" is accomplished through the teacher's explanation and the interaction between teachers and students in class. In the study of software engineering courses, students generally feel as if to understand the book, closed the book but what was left, the students did not grasp the essence of the idea of software engineering, knowledge absorption and internalization is not good, need teachers to help in this process.

The United States first introduced the flipped classroom education model. In 2000, Maureen, of University of Miami, first introduced the achievements of the "flip" model of education in the curriculum. At the University of Baker et al. Proposed Zelda 
flip classroom teaching model through the network curriculum to guide students learning. In 2007, two American high school chemistry teachers, Bergmann and Sams, used the flipped classroom education model and found that the effect was much better than the traditional model. In 2007, Salman Khan recorded instructional video on the Internet for more people to learn, to establish a nonprofit online "Khan", will provide conditions for the full implementation of the flipped classroom. In recent years, with the gradual popularization of classroom in the United States and the achievements achieved, the "flipped classroom" has also become an educational mode of concern to the global educational community. In China, "flipped class" has become a research hotspot. Many front-line teachers and teaching and research staff in various universities and primary and middle schools have thrown themselves into this field of research, and applied the flipped classroom to the actual teaching process, and achieved better teaching results. In 2011, Shanghai Normal University Professor Li Jiahou the practice of flip classroom teaching mode in the city of Chongqing Jukui school. In 2014, the school of computer science of Tsinghua University also studied and implemented the flipped classroom and applied it to combinatorics.

Flip the classroom, also known as reverse class, is a form of blended learning, learning courses students usually by watching videos in the classroom, in the classroom through the discussion, students and teachers to solve the problem to complete the job. The "flipped class" is the first two stages of the students' learning process, "listening, reading and memory", which are placed outside the classroom and completed by the students themselves. The "Comprehension - Application" is put into class by the interaction between teachers and students. Flip the classroom is essentially the knowledge accept completed in class, put knowledge in the classroom, re organizing and planning of teaching time and space, change teachers and students in the teaching mode of role. Compared to the current educational model of software engineering, the flipped classroom education model can effectively solve the above problems and has the following advantages.

(1) advanced information technology support; (2) student centered, can fully mobilize the enthusiasm of students; (3) increase the interaction between teachers and students.

The software development method of "software engineering" undergraduate teaching focuses on the traditional software development method and object oriented, teaching content for flipped classroom more, such as structured analysis, structured analysis and object oriented design and object oriented design. These contents include modeling technology learning, such as UML, etc. these technologies and their tools are relatively simple, easy to master, and difficult is how to apply these technologies to specific software project analysis and design. Therefore, the modeling technology of the study on the course by watching the video, the analysis and design methods are difficult to grasp with the specific project in the classroom teaching, through the discu ssion of the communication between teachers and students, so that students can of these theories and methods have a more profound understanding and grasp.

\section{II. .PROJECT DRIVEN FLIPPED CLASSROOM TEACHING REFORM}

In order to improve students' ability to analyze and solve practical problems comprehensively, the project oriented teaching is adopted in the classroom teaching of software engineering specialty. We try to set up a project driven into the flipped classroom, with software engineering practice experience of the teachers as the project manager to arrange a complete specific software development tasks as flipping the classroom teaching activities, let students complete a better grasp of the industry of new technology in the process of meaningful tasks. Thus, knowledge construction and skill training are carried out at the same time of project practice. Specifically divided into the following 5 steps:

(1) Case introduction. The first step of project driven teaching is "case study", that is the teacher to prepare in advance of engineering case teaching materials, students will be introduced to the teaching content of the situation by setting realistic problems in a specific project or display form. The students are divided into groups, each of which has a clear division of roles and 
cooperation with each other. Among them, team role is composed of project manager, configuration administrator, Requirement Analyst, system designer, programmer and tester.

(2) Concept inquiry. In traditional classroom, concept learning is mainly dependent on the teacher's lecture. However, due to the difference between students and the limited time, the students' learning of basic concepts is very dependent on the teaching progress of the teachers. In the flipped class, the basic concept of learning is completed by the students through the teaching resources provided by the teachers themselves. They can freely control themselves according to their own learning characteristics and time. For complex concepts, you can learn, think deeply, and meet difficult knowledge, you can discuss and exchange with your classmates.

(3) System construction. "System construction" refers to the students in the concept of inquiry on the basis of the relevant concepts and knowledge to establish a link between each other, the use of our knowledge map and mind map to achieve knowledge of the system. In order to help students strengthen the understanding of knowledge, we provide students with knowledge maps and mind maps at the stage of conceptual inquiry, so as to expand the teaching resources and enable students to construct meaning in a more adequate time. For students in the construction process of the problems encountered, on the one hand, through online communication platform to ask questions, on the other hand, can be held in class open discussion.

(4) Internalization of knowledge. On the basis of the previous stage, students need a higher level of transfer and application of self-study knowledge, so as to grasp the ability to solve problems, such ability generally needs to be acquired in the knowledge internalization stage. In the theoretical classroom that turns the classroom, we will organize the classroom report or the respondent around the question which is arranged by self-study before class. In this process, students are the subject of classroom discussion, teachers play a guiding and management role, and for all students of common problems, teachers can conduct specific explanations.

(5) Knowledge solidification (project development). In the experimental class, with the specific project and task oriented, and the first stage of "case study" echoes, students in the practice of software development related knowledge points, check the master, and complete the application and extension of knowledge expansion, the curing effect of learning. This stage is also an important part of training students' sense of cooperation and communication ability, and the task of teachers is to find out the problems of students and correct them in time.

(6) Feedback and evaluation. According to the students' knowledge and feedback, the teachers sum up the deficiencies in the teaching process so as to adjust the teaching content and teaching methods. The teachers consider two main aspects in the evaluation of students, one is according to the students to watch video, answer questions and communicate in the Internet; the two is based on the performance of students in the classroom, including the student in charge of the work of the difficulty and workload, in the degree of participation in the group, and the teachers and other students interaction etc.. The teacher will feedback the evaluation result to the students in time to help them find their own problems and make progress.

\section{PRACTICE OF TEACHING METHODS BASED ON FLIPPED CLASSROOM}

Through the practice of software engineering courses, the teaching method has effectively improved the quality of teaching, and the following aspects should be paid attention to in implementing the teaching method:

(1) The division of teaching units as far as possible "can be practice" as a unit of division

In the division of teaching units, we should try to divide the "practice" into units, so that we can concentrate our efforts on the engineering practice. Taking software engineering course as an example, the teaching unit can be divided into the following units: requirements analysis, overall design, detailed design, coding and unit testing, system testing and release, system maintenance.

(2) The reversal of practice part is mainly based on confirmatory practice and imitative practice, supplemented by creative practice 
Due to the abstraction of knowledge of software technology specialty, the course has a certain degree of difficulty in the teaching process in order to assist the understanding of related knowledge often requires verification and imitation practice, this part of the practice of the low degree of difficulty, can turn to the outside.

The practice of integrated project does not require that it be completed before class. It can be tried and practiced. It is mainly completed in the practice after the teacher has supplemented and explained it.

(3) Provide pre class learning resources should pay attention to the practical part of the guidance

Different from the general courses, the teaching of integrated courses should pay more attention to the guidance of the practical part, the content of the theme is clear, and the form of micro courses and video based. To practice guidance, we should pay special attention to the details and consistency, because the practice part, if there is a step failure, often leads to subsequent steps can not be carried out. If the practice conditions are limited, the virtual simulation software can be used to complete the initial practice.

(4) Classroom teaching should make full use of students' pre - class learning and practical results

Before part of the practice turns to class, on the one hand, students prepare knowledge, carry out preliminary practice, acquire the basic practical experience; on the other hand, teachers can learn the students' learning situation and practice results.

\section{CONCLUSION}

Through the implementation of the project in the "software engineering" in the course of driving and flipping the classroom with the combination of teaching mode and solves the disadvantages of traditional teaching mode, to enable students to become active participants, to stimulate students interest in learning, play the subjective initiative of students, effectively promote the student to the internalization of knowledge, teaching effect significantly improved. However, the reversal of classroom teaching model requires students to self-study before class, otherwise the teaching effect is very poor, and how to ensure that students can study consciously, need further exploration.

\section{ACKNOWLEDGMENT}

This work was supported by Taian City Science and Technology development project (grant No.20122057) and Taishan University Young Teacher Research Fundation project(grant No.QN-02-201602).

\section{REFERENCES}

[1] Zhang Yueguo, Zhang Yujiang.,"On the flip the classroom,” Education of Information Technology, 2012 ,vol 3 pp 47-49.

[2] Song Zhaoxia, Yu Qiding,"Research on Project-based Teaching Model Based on flipped classroom,” Distance Education, 2014,vol 1,pp. 96-104.

[3] Zhang Xiaochuan," Training system of practical ability for software engineering students," Computer Education, 2013, vol 16,pp. 1-8. 